González Guarda, C. ¿Es posible una criminología organizacional crítica? Los aportes de los 'Estudios críticos dq\} gestión" a la observación político -criminal del sistema penal. Derecho y Ciencias Sociales. Octubre 2017. № 17. (Estudios actuales sobre la justicia penal) Pgs 116-144 ISNN 1852-2971. Instituto de Cultura Jurídica y Maestría en Sociología Jurídica. FCJ y S. UNLP

\title{
¿Es posible una criminología organizacional crítica? Los aportes de los "Estudios Críticos de la Gestión” a la observación político-criminal del sistema penal
}

\author{
Is Critical Organizational Criminology Possible? Contributions of Critical Management \\ Studies to the political-criminal observation of the penal system.
}

\section{Claudio González Guarda•}

\section{Resumen:}

El presente artículo explora los potenciales aportes que los denominados Estudios Críticos de la Gestión (ECG) pueden hacer a la política criminal y a la criminología. Al objeto de contextualizar este trabajo nos referimos a los principales estilos que puede adoptar una investigación político criminal en el campo organizacional; enfocándonos en el estilo crítico dado que asumimos que es aquel donde primordialmente serán de utilidad los ECG. Para abogar por la consolidación de una "criminología organizacional crítica", indicamos 10 posibles temáticas organizacionales que podrían ser objeto de una investigación político criminal: 1.- La micro-gestión del sistema penal, 2.- El paradigma cliente-usuario, 3.- Las relaciones de género y gestión, 4.- Las relaciones laborales y distribución de poder, 5.- Gestión y tecnologías, 6.- Lenguaje del cambio organizacional, 7.- Paradojas y ambigüedades organizacionales. 8.- Cultura organizacional, 9.Debate de lo público y privado, y 10.- Empowerment y emancipación organizacional. Concluimos la pertinencia de estas nuevas herramientas teóricas y metodológicas para la política criminal.

Palabras claves: Política criminal, Organización, Críticos, Management, Criminología.

\section{Abstract:}

This article explores the possible contributions that so-called Critical Management Studies (ECM) can offer to criminal policy and criminological research. To contextualise this work, we focus on the main styles that a criminal research policy could adopt within the organizational field; focusing on the critical style, since it is assumed that this is where ECG will be of primary use. In order to advocate the consolidation of "critical organizational criminology", we indicate 10 possible organizational themes that could be the object of a criminal investigation policy: 1. - Micro-management of the penal system, 2. - The client-user paradigm, 3. Gender relations and management, 4. - Labour relations and distribution of power, 5. - Management and technologies, 6. - The language of organizational change, 7. - Paradoxes and organizational ambiguities. 8.Organizational culture, 9.- The public versus private sector debate, and 10.- Empowerment and organizational emancipation. We conclude by arguing these new theoretical and methodological tools for future criminal policy research.

Key words: Criminal policy, Organization, Critics, Management, Criminology.

\footnotetext{
- Autor: Dr. en Derecho penal y Política criminal, postgraduado en criminología, posgrado en ciencias cognitivas, Universidad de Málaga. Ex-becario Conicyt-Chile. cjgonzalezg@gmail.com.
}

Recibido 26/07/2017 Aceptado con correcciones 11/10/2017 
González Guarda, C. ¿Es posible una criminología organizacional crítica? Los aportes de los 'Estudios críticos dqłpa gestión" a la observación político -criminal del sistema penal. Derecho y Ciencias Sociales. Octubre 2017. № 17. (Estudios actuales sobre la justicia penal) Pgs 116-144 ISNN 1852-2971. Instituto de Cultura Jurídica y Maestría en Sociología Jurídica. FCJ y S. UNLP

\section{¿Es posible una criminología organizacional crítica? Los aportes de los "Estudios} Críticos de la Gestión" a la observación político-criminal del sistema penal

\section{Claudio González Guarda}

\section{Introducción}

Tradicionalmente los modelos de gestión y las estructuras organizacionales del sistema penal no han sido suficientemente tratados por las disciplinas que estudian el fenómeno del crimen y de la criminalidad. Las aproximaciones científicas se han centrado así en determinar aspectos más bien descriptivos y/o normativos de las organizaciones y agencias del sistema de justicia. Lo anterior probablemente derive de la idea equivocada de que en general la dimensión organizacional solo cumple un papel secundario en los procesos de criminalización del sistema penal.

Sin embargo, esto no ha sido siempre así, ya la criminología y la sociología de la desviación, especialmente norteamericana, de las décadas de los 60 y 70 se interesó en cómo los sujetos que ingresaban al sistema penal sufrían un proceso de etiquetamiento por parte de las organizaciones de justicia penal lo que constituía un especial proceso de criminalización. La corriente que más se interesó en este fenómeno fue la denominada "teoría del etiquetamiento" o Labelling Theory.

Sin embargo, en la actualidad "la organización" como objeto científico ha cobrado importancia especialmente por la emergencia de fenómenos como el gerencialismo y el actuarialismo penal, y en general por todos los epifenómenos, organizacionales o normativos, que emergen de la llamada penalidad neoliberal. A partir de ello nuestro trabajo pretende poner sobre relieve a la organización como objeto de estudio político criminal, utilizando a tal efecto una novedosa línea de investigación presente a día de hoy en diversas disciplinas de las ciencias sociales como la economía, las ciencias administrativas, la sociología y la antropología económica; nos referimos a los denominados Estudios Críticos del Management o de la gestión (ECM o ECG). ${ }^{1}$

\footnotetext{
${ }^{1}$ Acerca del uso del concepto management en política criminal, aunque en González-Guarda (2016) lo utilizamos como sinónimo de gestión, nos parece que la palabra manejo es la más adecuada para describir la actividad compleja, multifacética y moduladora de la política-criminal referida a la gestión. El problema surge porque management es un concepto poliédrico, así, en economía se suele usar como: dirección, gestión,
} 
González Guarda, C. ¿Es posible una criminología organizacional crítica? Los aportes de los 'Estudios críticos dq\} gestión" a la observación político -criminal del sistema penal. Derecho y Ciencias Sociales. Octubre 2017. № 17. (Estudios actuales sobre la justicia penal) Pgs 116-144 ISNN 1852-2971. Instituto de Cultura Jurídica y Maestría en Sociología Jurídica. FCJ y S. UNLP

A tal efecto, dividiremos nuestra exposición en cuatro secciones: en la primera contextualizaremos el uso de esta nueva herramienta teórica y metodológica, explorando las diversas alternativas que puede tomar una investigación en política criminal, centrándonos en el posicionamiento y los objetivos perseguidos por el investigador. En segundo lugar, describiremos brevemente el desarrollo de la criminología crítica por ser esta corriente la tendencia prioritaria desde donde los ECG pueden aproximarse a la investigación del sistema penal. La sección tercera abordará los ECG propiamente tales, explicando su evolución y desarrollo. Posteriormente, indicaremos 10 campos temáticos donde podría darse la relación entre los ECG y la investigación político criminal. Finalmente, haremos unas conclusiones generales.

\section{1.- Los diversos estilos de una investigación político criminal respecto del ámbito organizacional.}

A efectos de encuadrar nuestro trabajo es importante decir que en términos generales los estudios político criminales suelen aproximarse al fenómeno organizacional desde tres estilos diferentes: a) un estilo tradicional o descriptivo-valorativo, b) un estilo optimista o propositivo, y c) un estilo de carácter crítico o alternativo. Sin embargo, como es evidente, cualquier investigación al fin y al cabo será abordada por una combinación de los estilos previamente citados.

El estilo tradicional o descriptivo-valorativo está ligado normalmente a trabajos provenientes de perspectivas más bien jurídico-penales sobre la realidad organizacional. De este modo se hacen descripciones de carácter estructural del sistema normativo o bien se centran en los procedimientos de cómo las normas son aplicadas en la realidad de los tribunales de justicia o de las distintas agencias del sistema penal. Las líneas de trabajo más representativa de esta corriente corresponden al estilo de investigación desarrollado por el derecho procesal penal, por los estudios de naturaleza orgánica del sistema penal o por la misma dogmática penal. Así, el objeto de estas investigaciones queda constituido por las

gerencia y administración. Por ello, management, en otras áreas, no en política-criminal, pareciera ser el concepto más comprensivo. 
González Guarda, C. ¿Es posible una criminología organizacional crítica? Los aportes de los 'Estudios críticos dq ba gestión" a la observación político -criminal del sistema penal. Derecho y Ciencias Sociales. Octubre 2017. № 17. (Estudios actuales sobre la justicia penal) Pgs 116-144 ISNN 1852-2971. Instituto de Cultura Jurídica y Maestría en Sociología Jurídica. FCJ y S. UNLP

normas instrumentales, de procedimientos, por las atribuciones y competencias de los órganos judiciales. Todo lo anterior materializado finalmente en disciplinas como el derecho procesal orgánico y el funcional. ${ }^{2}$

Por otra parte, el enfoque investigativo propositivo u optimista, normalmente está asociado con aquellos trabajos desarrollados desde el amplio espectro de la teoría de las políticas públicas. Quienes participan de esta corriente normalmente asumirán a la política criminal no solo como disciplina científica sino también indicarán a la actividad política, como objeto de investigación, asumiendo que la política criminal es en esencia política pública, y por tanto un método de transformación social. ${ }^{3}$ Las disciplinas y sujetos que intervienen en esta perspectiva es amplia, lo que se expresa en la existencia de una serie de metodologías y perspectivas epistemológicas. Una tendencia sobresaliente, pero no la única, y que se ha apoderado del discurso de esta perspectiva político criminal es la denominada criminología administrativa. ${ }^{4}$ Uno de los métodos usuales en los que se concreta esta línea de trabajo son las denominadas "buenas prácticas". Ciertamente no existe un concepto exacto sobre esta materia para la política criminal, pero a partir de la literatura proveniente de las políticas públicas, podemos sostener que "una buena práctica político criminal se refiere a las experiencias, iniciativas o modelos de actuación exitosos que mejoran los procesos o que permiten resultados satisfactorios respecto de una determinada política pública del ámbito penal o criminológico". 5

\footnotetext{
${ }^{2}$ Ejemplos de este tipo de trabajos son: Binder, A. M, (1991). El proceso penal; Binder, A. M. (1993). Introducción al derecho procesal penal; Maier, J. B., Ambos, K., Woischnik, J, (2000). Las reformas procesales penales en américa latina; Maier, J. B. (2002). Derecho procesal penal I, fundamentos.

${ }^{3}$ Autores de referencia en el contexto hispanoamericano de esta línea política criminal son: Díez Ripollés, (2011). Dimensión exclusión/inclusión social como guía de la política criminal comparada; Binder, (2010). La política criminal en el marco de las políticas públicas. Bases para el análisis político criminal; Bustos y Hormazábal, (1997). Lecciones de derecho penal; Bustos y Hormazábal (2004). Nuevo sistema de derecho penal.

${ }^{4}$ La preponderancia de esta tendencia se plasmaría en lo que denominamos la Política Criminal Aplicada (PCA), la cual consistiría: "En la creación de un cúmulo de herramientas conceptuales y acciones concretas para su aplicación inmediata en el contexto del manejo o gestión del sistema penal. Las cuales se materializan desde la política pública o desde la práctica del control penal. Con participación preferente, pero no exclusiva, de la política legislativa penal". (González-Guarda, 2017).

${ }^{5}$ Ejemplo de este estilo son los trabajos del Centro de Estudio de la Justicia de las Américas (CEJA). Así en su página electrónica (www.ceja.org) es posible acceder a una nutrida información sobre distintos temas organizacionales del sistema de justicia, como seminarios o relatos de experiencias sobre análisis estadísticos o modelos de gestión judicial, ejemplo de esto son Pastor y Maspós (2001) en "Cifrar y descifrar: manual para generar, recopilar, difundir, homologar estadísticas e indicadores judiciales". Y también, Palma y Passos de Freitas (2015) en "Administradores de corte: opiniones de expertos".
} 
González Guarda, C. ¿Es posible una criminología organizacional crítica? Los aportes de los 'Estudios críticos dę gestión" a la observación político -criminal del sistema penal. Derecho y Ciencias Sociales. Octubre 2017. № 17. (Estudios actuales sobre la justicia penal) Pgs 116-144 ISNN 1852-2971. Instituto de Cultura Jurídica y Maestría en Sociología Jurídica. FCJ y S. UNLP

Respecto al estilo investigativo crítico, como es sabido, tiene una larga tradición especialmente dentro de la criminología, siendo influido fuertemente por los desarrollos teóricos críticos de las ciencias sociales. En términos muy generales a estas escuelas críticas se les suele posicionar como las contradictorias naturales respecto a los dos estilos anteriores, pero lo cierto es que pueden ser perfectamente complementarias. A la línea crítica nos referiremos con detalle en el epígrafe siguiente. ${ }^{6}$

Sin duda cualquiera de los tres estilos narrados con anterioridad puede abordar los objetos clásicos de una investigación acerca del crimen y de la criminalidad, a saber: sujeto criminal, víctima, organismos policiales, normas penales y procedimentales, sistema penitenciario, agencias del sistema penal, etc. Sin embargo, cuando se trata de investigar la dimensión organizacional del sistema de justicia penal, es constatable que la mayoría de los estudios se realizan históricamente desde estilos predominante normativos y "optimistas", es decir, que apuntan esencialmente a temas orgánico-descriptivos (normas, estatutos, instituciones, etc.) rehuyendo de este modo la discusión "crítica" que puede darse en el "núcleo organizacional" del sistema penal. ${ }^{7}$

Por tanto, tradicionalmente los estudios de estilo crítico o alternativo han centrado sus esfuerzos científicos en rebatir argumentos presentes en la dimensión normativa del sistema penal olvidándose en parte de los contenidos epistemológicos-organizacionales que componen sus instituciones. En este artículo proponemos explorar el amplio acervo conceptual y metodológico que ofrecen los denominados estudios críticos del management, y que pueden otorgar una ayuda a las perspectivas críticas al objeto de superar la limitación epistemológica en la que actualmente se encontraría, o tal como agudamente lo indica Van Swaaningen (2011:1), "la recuperación de la criminología crítica es necesaria para desafiar la disuasiva ética utilitaria y, así, preservar su estatus de campo de trabajo académico independiente". A esta tendencia, la hemos denominado, a falta de un mejor nombre, "criminología organizacional crítica".

\footnotetext{
${ }^{6}$ Podríamos entender como visiones críticas de la dimensión organizacional del sistema penal las referidas al "actuarialismo penal" o a la "penalidad neoliberal" en general. Obras relevantes son los trabajos de pioneros de Feeley y Simon, The New Penology y Actuarial Justice (1992) y The Emerging of a New Criminal Law (1994). También Harcourt (2013). Política criminal y gestión de riesgos. En el contexto hispanohablante destaca Brandariz-García (2016), El modelo gerencial-actuarial de penalidad. Eficiencia, riesgo y sistema penal.

${ }^{7}$ Sin perjuicio de una "supuesta" debilidad de "los estudios organizacionales críticos del sistema penal", es necesario destacar el histórico aporte que han hecho los abolicionistas penales como Nils Christie, Louk Hulsman y Thomas Mathiesen, quienes al poner en entredicho la normatividad penal cuestionaron de la misma forma la dimensión organizacional del sistema penal. También son destacables los trabajos de Stanley Cohen y LoÏc Wacquant a este respecto.
} 
González Guarda, C. ¿Es posible una criminología organizacional crítica? Los aportes de los 'Estudios críticos deła gestión" a la observación político -criminal del sistema penal. Derecho y Ciencias Sociales. Octubre 2017. № 17. (Estudios actuales sobre la justicia penal) Pgs 116-144 ISNN 1852-2971. Instituto de Cultura Jurídica y Maestría en Sociología Jurídica. FCJ y S. UNLP

\section{2.- Las corrientes críticas en la política criminal y la criminología.}

Históricamente cuando el derecho penal, la política criminal y la criminología se plantean desde perspectivas críticas suelen apoyar la construcción de sus marcos teóricos en la larga tradición de las ciencias sociales y de la filosofía crítica. Es notable en este sentido la influencia que en el siglo XX tuvieron la escuela crítica de Frankfurt o las líneas provenientes desde la visión neo-marxista de la sociedad.

Evidentemente esta tradición crítica se ha materializado con fuerza en el desarrollo de la criminología radical, crítica o marxista surgida a fines de los años 60 y principios de los setenta, coetánea además con el apogeo de los movimientos contraculturales que se suscitaban en distintas partes del mundo y cuyos impactos en nuestro contexto científico fue intensa, siendo este proceso ampliamente relatado por la literatura del área (Pavarini, 1983; Baratta, 1982; Taylor, Walton y Young, 1981). ${ }^{8}$ Para ciertos autores (no todos particularmente críticos) "algunos" de los principales postulados de la criminología crítica pueden resumirse en: inicialmente la criminología crítica fue una teoría de inspiración marxista, consideraba así que el fenómeno de la desviación solo puede ser analizado dentro del contexto socioeconómico en que se produce. También se suele decir que la estructura donde se ha desarrollado la criminología crítica corresponde al capitalismo tardío, en el cual impera el paradigma del conflicto y no del consenso, de esta forma, los comportamientos sociablemente negativos se explican según la clase social a la que pertenece el autor, mientras no desaparezca la sociedad capitalista corresponde aplicar un derecho penal mínimo y por tanto, a largo plazo el objetivo es la abolición del derecho penal y de la cárcel (Aebi, 2008: 285-287). ${ }^{9}$

\footnotetext{
${ }^{8}$ En lo que respecta a Latinoamérica hubo autores que se distinguieron con nombres propios como Lolita Aniyar de Castro o Raúl Eugenio Zaffaroni, quienes realizaron la aclimatación de esta escuela a la realidad de la región. Posteriormente esta visión decayó, y a fines de los ochenta y principio de los noventa su menor influencia se vio potencia por la llegada a la región de las nuevas visiones pragmáticas del sistema penal, especialmente aquellas derivadas de las escuelas norteamericanas que propendían aproximarse al crimen y la criminalidad a través de lo que se ha denominado la criminología administrativa.

${ }^{9}$ Se puede considerar como un replanteamiento moderno de las corrientes críticas los trabajos de Malcom, M. Feeley, Pat O`Maley, John Pratt o de Jonathan Simon. Pero sin duda la obra de mayor trascendencia ha sido el trabajo de David Garland, por ejemplo en: The Culture of Control-Crime and Social Order in Contemporary Society (2001); Punishment and Modern Society: A Study in Social Theory (1990), o bien, en Garland y Sparks, (2000), Criminology and Social Theory.
} 
González Guarda, C. ¿Es posible una criminología organizacional crítica? Los aportes de los 'Estudios críticos dęa gestión" a la observación político -criminal del sistema penal. Derecho y Ciencias Sociales. Octubre 2017. № 17. (Estudios actuales sobre la justicia penal) Pgs 116-144 ISNN 1852-2971. Instituto de Cultura Jurídica y Maestría en Sociología Jurídica. FCJ y S. UNLP

El desgaste de esta escuela se produjo por una combinación de causas; al agotamiento teórico y al surgimiento de problemas epistemológicos, se unió la escases de fundamentos empíricos para respaldar sus propuestas (Aebi, 2008). ${ }^{10}$ De esta falta de respaldo empírico se derivó el hecho que sus críticas no tuvieron acogida en los decidores políticos, quienes al fin y al cabo requerían y necesitaban respuestas punitivas rápidas y aplicables a contextos donde lo que imperaba era la formación de un nuevo modelo de seguridad ciudadana.

Autores como Larrauri (1991:192-193) sitúan la crisis de la criminología crítica en los años ochenta, crisis que se caracteriza por una cierta "confusión" debido a las reconsideraciones a las que se someten el bagaje de ideas de la década de los sesenta, así como también al surgimiento de nuevos movimientos sociales que cuestionaron a la criminología crítica y que volvieron difícil encuadrarlos dentro de la izquierda o de la derecha. También se habría observado una cierta "división" por la aparición de nuevas tendencias dentro de la criminología crítica, observándose finalmente un cierto "desánimo", debido a que las transformaciones sociales a las que se aspiraba parecieron inalcanzables y los experimentos penales alternativos devinieron en algo más propio de la sociedad disciplinaria.

Como es sabido la mayoría de los estudios críticos, con justa razón apuntaban a revelar las inequidades del sistema en su conjunto, la impunidad de los delitos de cuello blanco y en términos más extremos llamaban a abolir el sistema dada su inutilidad y selectividad arbitraria. En términos menos macrosociológicos, estas líneas críticas también pusieron su acento en el individuo como objeto de control por el sistema penal, especialmente se centraron en estudios del sujeto en los diferentes sistemas carcelarios, en el origen de la delincuencia juvenil y en las trayectorias de vida, entre otras temáticas.

Sin embargo, a pesar de la disminución del protagonismo de la criminología crítica en la actualidad, siendo desplazada por la criminología administrativa, creemos que al menos hay tres buenas razones para reflotar su espíritu crítico y fortalecer su capacidad

\footnotetext{
${ }^{10}$ Una crítica medular a las "perspectivas críticas" es el hecho de que se habrían desatendido del estudio de los problemas reales de la delincuencia menor, especialmente en los barrios céntricos pobres de las ciudades, los que a pesar de presentar crímenes leves y medianos, son masivos y perturban la vida de la población (Van Swaaningen, 2011). De esta crítica, emerge irónicamente una de las conclusiones criminológicas más notables de la actualidad: La evidencia empírica que demuestra que la mayoría de los delitos, al menos los clásicos, como robos, hurtos, lesiones, homicidios se producen dentro de las mismas clases sociales excluidas, es decir, más que constituir un segmento social oprimido en su generalidad por el sistema penal, se trata de una compleja interacción entre ofensores-victimas dentro de un mismo contexto espacio-temporal.
} 
González Guarda, C. ¿Es posible una criminología organizacional crítica? Los aportes de los 'Estudios críticos dę̧ gestión" a la observación político -criminal del sistema penal. Derecho y Ciencias Sociales. Octubre 2017. № 17. (Estudios actuales sobre la justicia penal) Pgs 116-144 ISNN 1852-2971. Instituto de Cultura Jurídica y Maestría en Sociología Jurídica. FCJ y S. UNLP

propositiva mediante el estudio crítico de las organizaciones de justicia penal. Estas razones son:

a).- La existencia en la actualidad de muchos fenómenos delictivos que escapan a la clásica concepción personalista del delito reflejada en la tríada: ofensor/víctima/delito. Así, hoy en día muchos delitos se desarrollan dentro y/o mediante organizaciones o entidades colectivas, públicas o privadas, lo cual necesariamente implica cambiar el paradigma de análisis criminal para su comprensión. De este tipo de delincuencia es la denominada criminalidad organizada, nacional o transnacional, o a las nuevas formas corrupción política y/o empresarial. Una de las expresiones de esta transformación es la implementación en diversos países de una legislación que hace penalmente responsable a las personas jurídicas. ${ }^{11}$

De este modo, este nuevo concepto del fenómeno criminal obliga a la criminología (crítica) a conocer el funcionamiento de las organizaciones y los modelos de gestión de las mismas, especialmente ante el peligro de que tras las supuestas "modernizaciones penales" que han extendido la punibilidad a las empresas o entidades colectivas, lo que realmente se esconde es la creación de "nuevas bolsas" de impunidad.

b).- Un segundo elemento está referido a la fuerte irrupción de nuevos modelos de control penal asociados ya no solo a la privación de libertad del sujeto sino que también a controles de carácter electrónico, telemático o virtual, o de naturaleza semejante. En todos estos casos, a efectos de que puedan operar adecuadamente es relevante que se hagan con un determinado modelo de gestión y organización. Por ello, dado que no tenemos en la actualidad una teoría general del manejo o gestión político criminal se hace necesario comprender estas prácticas desde los contenidos que la teoría de las organizaciones y el management ofrece.

Así, para realizar una evaluación crítica más allá de lo estrictamente penal, de estas nuevas herramientas punitivas, será necesario no solo observar su legitimidad y pertinencia en

\footnotetext{
${ }^{11}$ En nuestro contexto algunos de los países que han avanzado en este tipo de legislación son por ejemplo en Chile con la Ley $\mathrm{N}^{\circ} 20393$ del año 2009, España con la modificación del Código penal mediante la L.O 5/2010, Perú en la Ley $\mathrm{N}^{\circ} 30424$ del año 2016. Para más información ver en: Zugaldía y Marín de Espinosa, (2015). La responsabilidad criminal de las personas jurídicas en Latinoamérica y España.
} 
González Guarda, C. ¿Es posible una criminología organizacional crítica? Los aportes de los 'Estudios críticos del4 gestión" a la observación político -criminal del sistema penal. Derecho y Ciencias Sociales. Octubre 2017. № 17. (Estudios actuales sobre la justicia penal) Pgs 116-144 ISNN 1852-2971. Instituto de Cultura Jurídica y Maestría en Sociología Jurídica. FCJ y S. UNLP

cuanto a los derechos que pudieran vulnerar, o la rentabilidad social-penal que debiéramos asumir; sino que también deberemos valorar qué modelo de gestión es más coherente con una política criminal sensata y racional.

c).- El último punto, y en conexión con el anterior, está referido a la preponderancia que actualmente están asumiendo perspectivas como el gerencialismo, el actuarialismo penal o la búsqueda de eficiencia dentro del sistema penal. Para dar cabida a todos estos nuevos planteamientos teóricos es necesario previamente entender la configuración organizacional del sistema penal, lo que implica comprender cómo interaccionan sus diferentes niveles organizacionales, cómo se relacionan los ámbitos técnicos, culturales y políticos, y sobre todo, entender que al modelarse la cultura organizacional también se está modelando la política criminal del sistema penal en su conjunto.

En cada uno de estos puntos un enfoque político criminal apoyado en la teoría de las organizaciones puede ser de gran ayuda y una sugerente forma de reconfigurar los estudios críticos en el campo de la criminología. Por tanto, a continuación revisaremos el origen y evolución de los ECM, sus discusiones semánticas, así como también las críticas que se les han realizado.

\section{3.- Los estudios críticos de la gestión (ECG)}

\section{1.- Concepto y evolución}

Esta corriente en el contexto anglosajón, donde tuvo su origen, se le denomina los Critical Management Studies (CMS). En el contexto iberoamericano este campo disciplinar es conocido usualmente como Estudios Críticos de la Gestión, o de la administración, de la organización, o estudios críticos de la gestión empresarial, aunque muchos autores en la actualidad siguen la nomenclatura anglosajona. En nuestro caso, seguiremos el término de estudios críticos de la gestión (ECG). Así en palabras de Fernández (2007a) los ECG son:

"Un conjunto de trabajos e investigadores que hacen una aguda crítica a los supuestos sobre los cuales se ha construido el discurso en gestión, que reflexiona sobre el impacto que las herramientas y dispositivos del management han tenido en las prácticas organizacionales y propone, a partir del diálogo con la filosofía y con otras disciplinas de las ciencias humanas, construir una nueva agenda de reflexión centrada en problemas que han sido desdeñados por la teoría 
González Guarda, C. ¿Es posible una criminología organizacional crítica? Los aportes de los 'Estudios críticos dę gestión" a la observación político -criminal del sistema penal. Derecho y Ciencias Sociales. Octubre 2017. № 17. (Estudios actuales sobre la justicia penal) Pgs 116-144 ISNN 1852-2971. Instituto de Cultura Jurídica y Maestría en Sociología Jurídica. FCJ y S. UNLP

administrativa tradicional pero que son cada vez más relevantes para comprender el mundo organizacional contemporáneo: la dominación y el control en las organizaciones, los aspectos simbólicos y estéticos de la gestión, los procesos de subjetivación y construcción de la identidad en el lugar de trabajo, los problemas derivados de la discriminación racial y de género, la comunicación, la ideología, el poder, el conflicto, las implicaciones políticas de los dispositivos y prácticas del management, el lugar que ocupa el placer en la gestión, la búsqueda de la dignidad en el trabajo"

Extrañamente quienes critican el funcionamiento del sistema penal no suelen explorar esta importante fuente teórica crítica, que corresponde a una amplia línea de estudios críticos precisamente en el campo organizacional. Más bien ejercen su crítica desde posturas que podríamos denominar macro-sociológicas o macro-político-criminales.

Por otro lado, resulta evidente que aquellos prácticos y académicos que dan su bienvenida acrítica a las herramientas gerenciales están generalmente imbuidos por la enseñanza tradicional de la gerencia científica, especialmente a través de los Master of Bussines and Administration (MBA) o directamente mediante la formación de cuadros profesionales en las facultades de economía, de administración o de negocios.

Tales programas son herederos en su mayoría de la tradición taylorista y fayolista, potenciada por la obra de los padres del manejo actual, especialmente por la línea inaugurada por Peter Drucker (Fernández, 2008). Sin embargo, esta situación se ha morigerado, pues se ha producido un alejamiento del tronco gerencial histórico, para entrar en los estilos gerenciales "vanguardistas" propios de la nueva gestión pública (New Public Management), cercanos a la mercadotecnia y a una literatura del manejo centrada más en la autoayuda gerencial (gurús del management) ${ }^{12}$ que en la construcción objetiva y racional de la organización.

Como es normal en un nuevo campo interdisciplinar, no es posible determinar un big bang específico que nos indique el momento exacto de eclosión. Sí podemos decir que, de forma intensa en los últimos 15 a 20 años se ha logrado convertir en algo más que una tendencia, poseyendo ya un cuerpo importante de producción académica y de visibilidad científica a

\footnotetext{
${ }^{12}$ Fernández (2007a:340) dice que debemos entender por gurú del management a un hombre o mujer que ha conseguido un nivel notorio de conocimientos en el campo de la gestión empresarial y que puede ser un académico, un consultor u otro profesional. El mismo autor, en Fernández (2007b:10-13) expresa que las modas del management y el concepto "gurú del management" indiscutiblemente también contiene un cierto tono peyorativo por el carácter "cuasi místico" y acientífico que tienen muchos de los remedios y recomendaciones organizacionales que promueven.
} 
González Guarda, C. ¿Es posible una criminología organizacional crítica? Los aportes de los 'Estudios críticos dę gestión" a la observación político -criminal del sistema penal. Derecho y Ciencias Sociales. Octubre 2017. № 17. (Estudios actuales sobre la justicia penal) Pgs 116-144 ISNN 1852-2971. Instituto de Cultura Jurídica y Maestría en Sociología Jurídica. FCJ y S. UNLP

través de revistas especializadas, ${ }^{13}$ contando hoy en día con una comunidad especializada que se organiza en coloquios, congresos, etc., siendo Manchester una de las cunas de este movimiento.

Sin embargo, a pesar de existir literatura crítica de las organizaciones previa a la configuración contemporánea de este campo disciplinar, pareciera haber cierto consenso en que el origen de los ECG estaría ligado al campo de las denominadas ciencias del trabajo, siendo relevante en este sentido la obra de Harry Braverman (1974) "Trabajo y capital monopolista", que aportó la denominada "teoría del proceso de trabajo". Esto, como indica Fernández (2007a: 349) "supone una revolución teórica en los estudios sobre la organización del trabajo...con un nuevo enfoque que revitalizaba el marxismo y primaba el estudio del proceso concreto del mismo (en el que Braverman denunciaba un proceso de descualificación del mismo llevado a cabo por la gestión científica del trabajo, con el fin de que las clases capitalistas se asegurasen el control de la producción y su poder de clase), y con un mayor énfasis en el lugar de trabajo, la fábrica”.

Esta visión, fue posteriormente criticada por poner el acento en elementos muy estructurales, objetivos y marxistas, donde el sujeto parecía estar ausente. Además, era un hecho que las condiciones económicas y el mundo del trabajo ya habían cambiado y, ya entrados en la década de los 80 se sumaba a este escenario el declive del fordismo y el paso hacia el toyotismo; en definitiva, la instalación de una nueva economía de la información y el conocimiento. Se adicionaba a lo anterior la visibilidad de la figura del gerente, la exhibición del éxito y de la prosperidad material, y el comienzo de lo que se llamó el "gerencialismo de la sociedad". Todo esto reclamaba una nueva mirada epistemológica de estos fenómenos y, de las organizaciones (Saavedra, 2009: 48 - 49).

La literatura de los ECG en nuestro ámbito cultural (por ejemplo, en Ramírez, 2000; Fernández, 2007a; Fernández, 2007b; Saavedra, 2009; Montaño, 2004, 2013) suele indicar que las zonas geográficas donde emergió esta corriente fue el Reino Unido primariamente, y luego también los EE.UU y países escandinavos, más tarde en Australia y Holanda. Los critters, que es el nombre con el que se habría conocido a este grupo de académicos críticos del management, habrían operado desde diferentes lugares, sobre todo en EE.UU o en el Reino Unido.

\footnotetext{
${ }^{13}$ Algunas de estas revistas son: Organizations, Culture and Organization, Organizations Studies, Journal of Management Studies, Journal of Management Inquiry, Tamara: Journal for Critical Organization Inquiry y Ephemera: Theory and Politics in Organisation.
} 
González Guarda, C. ¿Es posible una criminología organizacional crítica? Los aportes de los 'Estudios críticos delæa gestión" a la observación político -criminal del sistema penal. Derecho y Ciencias Sociales. Octubre 2017. № 17. (Estudios actuales sobre la justicia penal) Pgs 116-144 ISNN 1852-2971. Instituto de Cultura Jurídica y Maestría en Sociología Jurídica. FCJ y S. UNLP

En el país norteamericano estarían básicamente anidados en escuelas de ciencias sociales, antropología y sociología, mientras que en el caso británico habrían surgido desde visiones críticas enclavadas en el interior mismo de las escuelas de negocios (Ramírez, 2004). Esto último también fue constatado por un trabajo cualitativo de Fernández, el cual entrevistó a una serie de destacados académicos que dieron una imagen del escenario británico y europeo; como ilustra el autor, "no se debe olvidar que se trata de un grupo de académicos que hacen la crítica desde un lugar extraño, incrustados en un espacio destinado a formar a los futuros mandos de las grandes empresas" (Fernández, 2007a: 367).

Otra línea de avance en la consolidación del nuevo campo disciplinar está conectado con el trabajo de David Knights y Hugh Willmott, profesores del UMSIT de Manchester (University of Manchester Institute of Science and Technology), con su obra Labour Process Theory (1989). En ella, revisando a Braverman, trazaron una línea entre "los modernos" (investigadores), que estarían encarnados en la línea laborista británica, herederos de cierta forma del thatcherismo y promotores del New Labour, y otra línea "los postmodernos" - que estaría más cercana a los estudios de la cultura de la empresa.

Pronto este conglomerado de nuevos investigadores tomaría forma a través de una serie de congresos y libros hoy calificados de esenciales, que recopilaban poco a poco los incipientes trabajos en este campo. Entre ellos tenemos, por ejemplo, Critical Management Studies (1992) ${ }^{14}$ de Matt Alvesson y Hugh Willmontt, o Postmodernism and Organizations (1993) de Hassard, J y Parker, M. Esta última obra con referencia clara y explícita a la relación entre el nuevo marco teórico y las organizaciones. También, Resistance and Power in Organizations (1994), editado por Jermier, Knights y Nord, que investiga situaciones de resistencia y control dentro de las organizaciones (Fernández, 2007). Sin perjuicio de la consolidación disciplinar, para algunos, esta línea de investigación (ECG) es más bien una derivación de los denominados Estudios organizacionales (E. O) (Montaño, 2013: 30).

Los Estudios Organizacionales habrían surgido en la década de los setenta y serían herederos de los estudios analíticos de la teoría de la organización y administración, con una fuerte vocación multidisciplinaria y con profundas influencias del posestructuralismo, del neomarxismo y del constructivismo. Esta línea, en coherencia con la fundación del

\footnotetext{
${ }^{14}$ Según indica Ramírez (2000:8) este texto corresponde a lo que fue recogido y sistematizado a partir de una conferencia ofrecida en el Baruch College de New York, sobre "Perspectivas críticas del análisis organizacional" en 1985. A su vez, de ese texto emerge lo que es conocido como "el manifiesto" con el título de Make Sense of Management.
} 
González Guarda, C. ¿Es posible una criminología organizacional crítica? Los aportes de los 'Estudios críticos dę gestión" a la observación político -criminal del sistema penal. Derecho y Ciencias Sociales. Octubre 2017. № 17. (Estudios actuales sobre la justicia penal) Pgs 116-144 ISNN 1852-2971. Instituto de Cultura Jurídica y Maestría en Sociología Jurídica. FCJ y S. UNLP

Grupo Europeo de Estudios Organizacionales (1973), promovía los estudios de la cultura, el poder, el lenguaje y el género en las organizaciones, virando fuertemente en este tipo de análisis hacia disciplinas de las humanidades, como la filosofía, la antropología y la lingüística (Montaño, 2013: 27).

En lo que respecta a Iberoamérica, como suele ocurrir en muchos campos, las primeras obras han sido trabajos que básicamente dan cuenta de la recepción y divulgación de este nuevo enfoque y de su aclimatación desde sus focos originarios a nuestros contextos. Sin embargo, y ello en el caso español, lo cual es extrapolable al resto de la comunidad iberoamericana, no existía una institucionalización de estos estudios a diferencia de los países anglosajones o escandinavos, Fernández (2007a: 371-378). Con todo, ello no impide que exista una fuerte corriente de trabajos críticos respecto del mundo organizacional, especialmente a través de los estudios culturales o desde la sociología o la historia social. Lo mismo acontecería en las tradiciones francesas y alemanas.

En Latinoamérica, como la propia literatura acerca del desarrollo del management lo ha puesto en evidencia, somos parte de esa periferia de países "no desarrollados" que tenemos la calidad dual de receptores y divulgadores de la producción managerial de los "países desarrollados", la cual está actualmente configurada por la producción literaria norteamericana. Eso ha impedido la inserción de propuestas de la periferia en los mayores centros de debate, producción y difusión científica de este campo (Alcadipani, 2012).

A pesar de lo anterior, el panorama en cuanto a estudios críticos de la gestión parece estar cambiando, lo cual es particularmente importante para nosotros. Esperamos que pronto se configure una línea de esta naturaleza en el ámbito político criminal. En México los trabajos organizacionales de Montaño son particularmente relevantes (Montaño, 2004; Montaño, 2013). En Colombia un importante grupo adscrito a la Escuela de ciencias de la administración de la Universidad del Valle, a través del grupo "Nuevo pensamiento administrativo", ha acercado las ideas del grupo "Humanismo y gestión" del HEC de Montreal $^{15}$ a nuestro contexto. En general, tales trabajos están fuertemente inspirados por las posturas del humanismo radical de la gestión (Saavedra, 2009: 47). Para el caso brasileño, especial relevancia tienen las obras de Omar Aktouf.

\footnotetext{
${ }^{15}$ Prestigiosa escuela de negocios canadiense vinculada a la Universidad de Montreal. Es una de las escuelas de gestión más importantes del mundo, siendo conocida además por tener una línea humanista revisionista de los postulados clásicos de la gestión. Más información en http://www.hec.ca.
} 
González Guarda, C. ¿Es posible una criminología organizacional crítica? Los aportes de los 'Estudios críticos dęa gestión" a la observación político -criminal del sistema penal. Derecho y Ciencias Sociales. Octubre 2017. № 17. (Estudios actuales sobre la justicia penal) Pgs 116-144 ISNN 1852-2971. Instituto de Cultura Jurídica y Maestría en Sociología Jurídica. FCJ y S. UNLP

En Costa Rica los estudios críticos de carácter organizacional, han aparecido básicamente al hilo de los análisis hechos de los procesos de neoliberalización y precarización laboral, luego de una serie de intervenciones y ajustes estructurales que han sido aplicados en la economía "tica" desde la década de los 80 en adelante.

En el caso chileno, además de la tradición crítica proveniente de la historia social (Gabriel Salazar y Tomas Moulian por ejemplo), coherente con un país que necesitaba un relato que permitiera comprender el haber sido un experimento neoliberal pionero en la introducción de técnicas gerenciales en Latinoamérica, se ha ido configurando una incipiente comunidad de ECG conformada desde diversos campos, especialmente desde la sicología social (Sisto, 2012), las ciencias de la educación y la sociología económica. Ciertamente el tipo de management o, como dicen algunos autores, el "mainstream managerial" del sistema chileno es uno propio del modelo neoliberal. En el mundo del trabajo y de las organizaciones se estudian a través de este tamiz. Ramírez (2000) ya lo había indicado cuando reflexionaba sobre la nueva gestión pública. Sin perjuicio de las informaciones anteriores, una importante aproximación y resumen del paisaje de los ECG en Chile lo encontramos en Espinosa y Ramírez (2015).

\section{2.- Contenidos y aplicaciones de los estudios críticos de la gestión}

Visto brevemente el desarrollo de la disciplina de los ECG, corresponde ahora referirnos a ciertos elementos o temáticas de ellas que consideramos esenciales para nuestro trabajo.

\section{a).- Temas que trata esta tendencia}

Sin dejar de estudiar algunos de los elementos clásicos que la escuela funcionalista ha observado en las organizaciones, estos estudios centran su mirada en todos aquellos elementos sobre los que esta ha omitido pronunciarse, por ejemplo, la dimensión política, la construcción de las jerarquías o el poder, las culturas corporativas y gerenciales. Por lo mismo, no es de extrañar que sean críticos con el neoliberalismo y la globalización y que denuncien el racismo, el machismo, la coacción y el control en las organizaciones. De esta forma Fernández, trayendo a colación a dos de los padres de esta corriente, Alvesson y Willmott indica: 
González Guarda, C. ¿Es posible una criminología organizacional crítica? Los aportes de los 'Estudios críticos đÐ〕 gestión" a la observación político -criminal del sistema penal. Derecho y Ciencias Sociales. Octubre 2017. № 17. (Estudios actuales sobre la justicia penal) Pgs 116-144 ISNN 1852-2971. Instituto de Cultura Jurídica y Maestría en Sociología Jurídica. FCJ y S. UNLP

"El management no es una simple función técnica o neutral asociada a la producción de bienes o servicios: es un fenómeno social significativo y complejo, que debe ser objeto de un examen en profundidad..."

(Alvesson y Wiilmontt, 1992a, 1996 y 2003) (Fernández, 2007b:50).

"Los Critical Management Studies se centran en varios temas: la relación entre el poder y las prácticas discursivas en la empresa moderna, el análisis de las funciones en la empresa y el discurso que en ellas se maneja (marketing, sistemas de información, recursos humanos), el clásico problema de tecnocracia frente a democracia, el rol de la Teoría Crítica en la investigación organizativa o el análisis de opciones de emancipación en el trabajo y la vida organizacional" (Alvesson y Willmontt, 1992a; Alvesson y Deetz, 2001)." (Fernández, 2007b: 51).

b).- Marco teórico utilizado

El marco teórico está indisolublemente ligado a la pregunta de qué hace que cataloguemos esta escuela o tendencia como "escuela crítica". Para ello, debemos recordar la clasificación que hemos hecho antes entre modernistas o funcionalistas por un lado, y postmodernistas por el otro. Así también debemos traer a colación nuestra referencia en la sección primera de este artículo acerca de las diversas perspectivas político-criminales que se pueden asumir para abordar un fenómeno criminológico.

Los primeros (modernistas) responden a tendencias propias de la tradición de la gerencia científica, que están teñidas de una fuerte carga de racionalidad instrumental y desembocan en la perspectiva clásica de entender las organizaciones. La segunda línea (postmodernistas) por su parte, es decir, los estudios críticos de la gestión, básicamente aspiran a modificar "algunas" de las relaciones sociales al interior de las organizaciones (Montaño, 2013:31).

Por ello, sin ser una visión anti-administración, asume un marco teórico crítico y se aproxima para esa labor al posestructuralismo fundando su razón de ser en las ideas de la teoría crítica propia de las ciencias sociales, desciende en definitiva al paradigma crítico de la escuela de Frankfurt (Hockenheimer, Adorno, etc.). Está al mismo tiempo fuertemente influenciada por el pensamiento de Michael Foucault y por una variada gama de tendencias (visiones de género, postcoloniales, raciales etc.) y de autores posestructuralistas como Guattari, Deleuze, entre otros, (Ramírez, 2000: 14). 
González Guarda, C. ¿Es posible una criminología organizacional crítica? Los aportes de los 'Estudios críticos dÐధ̨ gestión" a la observación político -criminal del sistema penal. Derecho y Ciencias Sociales. Octubre 2017. № 17. (Estudios actuales sobre la justicia penal) Pgs 116-144 ISNN 1852-2971. Instituto de Cultura Jurídica y Maestría en Sociología Jurídica. FCJ y S. UNLP

c).- Innovación metodológica

Uno de los elementos más revolucionarios de esta línea de investigación crítica se da en el campo metodológico, especialmente por su tendencia al uso de la investigación cualitativa (etnografías, entrevistas cualitativas, observación participante, análisis del discurso, etc.) y de sus recursos siempre que estén disponibles para el estudio de las organizaciones. ${ }^{16}$ Elementos como cultura, poder, creencias y otros, así como la idea de sacar a la luz factores ideológicos y la subjetividad de los sujetos, han dado lugar a una nueva perspectiva epistemológica y metodológica.

La visión acrítica asociada a la teoría clásica gerencial y administrativa evidentemente tiene una tendencia hacia lo funcional y positivista, hacia una labor de cuantificación de los procesos propios de las organizaciones. En contraste a lo anterior, algunos autores han dicho que el rasgo diferenciador de los ECG es la "reflexibilidad"; es decir, la idea de esta perspectiva es fomentar la discusión epistemológica y promover propuestas alternativas, a contrario de lo que ocurre con las propuestas clásicas del management (Ramírez, 2000:13). Estas últimas buscarían otro tipo de objetivos como imponer ciertas posturas gerenciales, la explotación del ser humano, como objetivo la maximización económica (Solarte, 2013: 235).

d).- Críticas a los estudios críticos del management

Dentro de la diversidad de críticas que recibe esta corriente, una de las más intensas es la de que aún no estamos ante un cuerpo teórico completamente consolidado, lo cual es bastante discutible dadas las explicaciones que en párrafos anteriores hemos realizado. De hecho, se suelen esgrimir argumentos similares respecto del propio management histórico. Nos parece más aguda la visión de Montaño (2013) que, trayendo a colación a Forbes y Willmontt (2007), señala que la mayor crítica es probablemente la impotencia y la escasa influencia que estas líneas tienen aún en las organizaciones, además de que, a tenor del grave deterioro social actual (hambrunas, subempleo, desempleos masivos, crisis etc.), los cambios graduales son insuficientes. Textualmente cita Montaño (2013:31): "La forma más dañina de utopía es sin duda aquella que imagina que la injusticia salvaje y la

\footnotetext{
${ }^{16}$ El enfoque metodológico plural que impulsan los estudios críticos de la gestión como medio para revelar dimensiones menos visibles de las organizaciones, nos ha servido de inspiración para adscribirnos a la perspectiva cualitativa al momento de investigar el fenómeno gerencial en las realidades político criminales respectivas.
} 
González Guarda, C. ¿Es posible una criminología organizacional crítica? Los aportes de los 'Estudios críticos dø̨ gestión" a la observación político -criminal del sistema penal. Derecho y Ciencias Sociales. Octubre 2017. № 17. (Estudios actuales sobre la justicia penal) Pgs 116-144 ISNN 1852-2971. Instituto de Cultura Jurídica y Maestría en Sociología Jurídica. FCJ y S. UNLP

destrucción construidas al interior de la actual estructura social pueden ser remediadas por reformas tecnocráticas modestas... (Adler, Forbes y Willmontt, 2007: 154)".

Además de estas dos grandes críticas generales, la literatura suele estar bastante conteste en otra serie de críticas más específicas, las cuales son:

- Es excesivamente teórica y con una evidente falta de empirismo, especialmente en los trabajos más recientes que privilegian el tono ensayístico sobre el trabajo empírico.

- A propósito o como efecto de lo anterior, existiría el peligro de una deriva filosófica, lo que provocaría el olvido del núcleo del estudio, las organizaciones y las ciencias del trabajo.

- Un defecto, devenido probablemente por su cercanía con los estudios culturales, es que corre el riesgo de perder su objeto de estudio y enfocarse excesivamente en identidades o subjetividades.

\section{4.- 10 ámbitos concretos de aplicación para la investigación político criminal.}

Sin perjuicio de lo que hemos visto en la primera parte de este trabajo acerca de algunos aportes que los estudios organizacionales podrían ofrecer a la política criminal y particularmente a la criminología crítica, en esta sección abordaremos ciertos aportes concretos que los ECG pudieran ofrecer a la hora de aproximarnos a la dimensión organizacional del sistema penal. Ciertamente las áreas de trabajo a continuación mencionadas son solo algunas, no agotándose en ellas los posibles campos temáticos.

Como hemos venido diciendo, en términos generales los estudios organizacionales, y los ECG en particular, pueden brindarnos un novedoso y amplio marco teórico para el análisis de la dimensión organizacional del sistema penal. De esta manera, al menos para nuestro campo, superaríamos los análisis exclusivamente jurídicos respecto a cómo se estructura la política criminal en el campo de las organizaciones penales.

Lo anterior está estrechamente ligado a la tensión dialéctica entre pesimistas o críticos frente a optimistas, conformistas u oficialistas, respecto del rol de las políticas públicas en el campo penal. Esta tensión, anidada originalmente en la criminología o en el derecho penal, la podemos replicar en el campo organizacional, así, la resolución acerca de cómo se 
González Guarda, C. ¿Es posible una criminología organizacional crítica? Los aportes de los 'Estudios críticos dÐ3 gestión" a la observación político - criminal del sistema penal. Derecho y Ciencias Sociales. Octubre 2017. № 17. (Estudios actuales sobre la justicia penal) Pgs 116-144 ISNN 1852-2971. Instituto de Cultura Jurídica y Maestría en Sociología Jurídica. FCJ y S. UNLP

configurá el funcionamiento de las instituciones penales, puede llegar a tener igual o más importancia que el propio diseño normativo de las mismas.

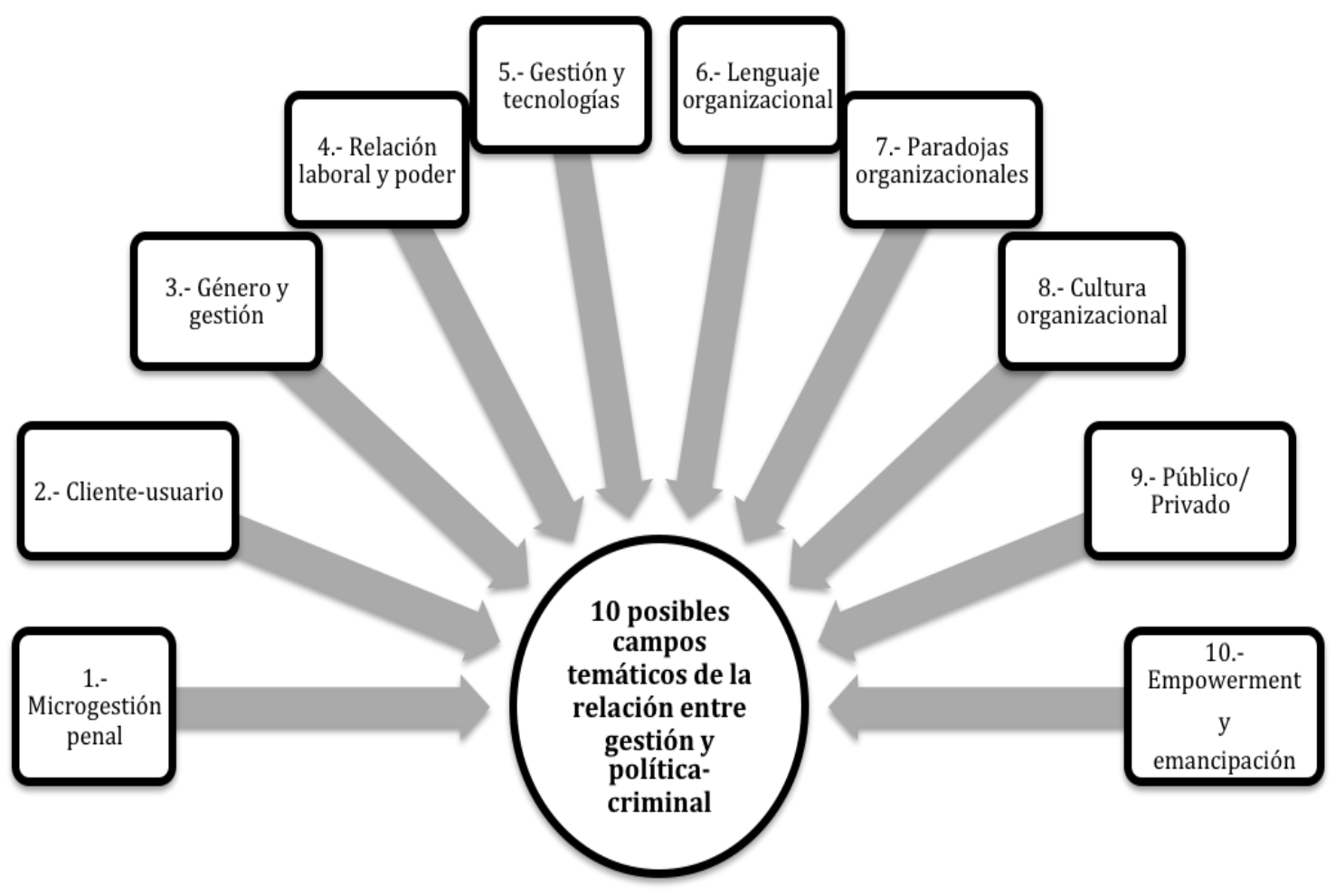

Fuente: elaboración propia.

1.- Estudio de la micro-gestión de los sistema penales: Es un hecho que la dimensión organizacional de las organizaciones de justicia penal contiene al menos dos ámbitos diferenciados, uno compuesto por la macro-gestión cercana a la macro-política criminal y otro, referido a la micro-política criminal, relacionado con la micro-gestión del sistema. A la macro-gestión normalmente se accede pesquisando las políticas públicas que han estructurado el sistema y que han delineado el funcionamiento general de sus instituciones. En el caso de la micro-gestión, por estar constituida de prácticas, rutinas y discursos difíciles de rastrear se hace necesario una metodología más "osada" a la hora de averiguar sus contenidos.

En este punto los ECG nos ofrecen las herramientas que contienen la etnometodología y la etnografía organizacional que nos permitirían develar esas prácticas intrínsecas de la 
González Guarda, C. ¿Es posible una criminología organizacional crítica? Los aportes de los 'Estudios críticos dÐ44 gestión" a la observación político -criminal del sistema penal. Derecho y Ciencias Sociales. Octubre 2017. № 17. (Estudios actuales sobre la justicia penal) Pgs 116-144 ISNN 1852-2971. Instituto de Cultura Jurídica y Maestría en Sociología Jurídica. FCJ y S. UNLP

micro-gestión procesal. ${ }^{17}$ Lo anterior es relevante pues muchas de las transformaciones orgánico-normativas de las que son objeto las instituciones de justicia, como por ejemplo un nuevo modelo de gestión, juegan su éxito o fracaso, no solo en el diseño de las mismas, sino también en las interacciones que se dan entre las pequeñas operaciones desarrolladas por los sujetos del sistema y las instituciones en las cuales están insertos.

\section{2.- La posibilidad de estudiar críticamente la relación de los}

clientes/usuarios/beneficiarios con las organizaciones de justicia: Uno de los rasgos característicos de la Nueva Gestión Pública (NGP) y de la Gestión por Resultados (GpR) es el trasvase de la filosofía de atención cliente-usuario desde el ámbito privado al contexto de lo público. Esta situación ciertamente también se ha comenzado a manifestar en algunos sistemas penales, especialmente a través de los programas de atención al cliente-usuario y su evaluación por empresas y consultorías privadas (auditorías externas). Lo cierto es que este fenómeno actualmente no tiene el tratamiento político-criminal adecuado, a pesar de que la "satisfacción" del cliente-usuario es el objetivo principal al que abogan las modernas líneas de la teoría de las organizaciones.

A partir de lo que observamos en la literatura que reflexiona acerca de este asunto en el sector público (Subirats, 1994; Barzelay, 1992; Chias, 1995: 32-34) ${ }^{18}$ es evidente que el concepto cliente-usuario está indefectiblemente unido al mundo y a la visión de los negocios privados, por tanto, su análisis en el contexto del sistema penal no solo deberá hacerse desde una perspectiva político criminal tradicional sino necesariamente desde

\footnotetext{
17 La etnografía judicial es cada vez más utilizada en diversas investigaciones, así por ejemplo desde la antropología judicial en: Sanjurjo, Liliana. (2016). "Las luchas por las memorias en la escena judicial: Una mirada etnográfica sobre los Juicios de Crímenes de Lesa Humanidad". En el ámbito de los estudios histórico judiciales o de la historia social de la criminalidad lo vemos en: Salinas, R, (2000). "Violencias sexuales e interpersonales en el Chile tradicional"; Leal, B, (2010). "Paulina Montaño demanda su libertad. Aproximación a una etnografía performativa de un pleito judicial , Chocó, 1738”. Desde una perspectiva ligada a la sicología social lo vemos en Cubells, J. e Íniguez, L. (2008). "La construcción de hechos en el discurso jurídico: Análisis del caso de los "robos en cajeros automáticos en la ciudad de Barcelona”. Desde la sociología jurídica lo vemos en Le Bonniec, F., (2014). ¿Hay discriminación en los tribunales del sur de Chile? Razones para una etnología del campo jurídico en la Araucanía.

${ }^{18}$ Existe un amplio debate sobre el concepto adecuado de cliente-usuario. Por ejemplo Barzelay (1992), argumenta para no recomendar el uso de la palabra cliente en el sector público, que en muchas situaciones el uso de la palabra cliente es algo más que pura retórica, ya que es un concepto que estructura argumentos para alcanzar objetivos y líneas de acción. El autor indica que el uso del término cliente promueve un alto nivel de confusión y pseudo-interpretaciones, ya que invoca conceptos muy diversos como usuario, beneficiario, aportador de fondos, coproductor y, ciudadano-propietario.
} 
González Guarda, C. ¿Es posible una criminología organizacional crítica? Los aportes de los 'Estudios críticos dÐ马 gestión" a la observación político -criminal del sistema penal. Derecho y Ciencias Sociales. Octubre 2017. № 17. (Estudios actuales sobre la justicia penal) Pgs 116-144 ISNN 1852-2971. Instituto de Cultura Jurídica y Maestría en Sociología Jurídica. FCJ y S. UNLP

perspectivas organizacionales. Es en este punto donde los ECG pueden ayudarnos, especialmente cuando a estos sujetos se les ha empoderado como "consumidores" de un ambiguo producto llamado "justicia penal".

Un ejemplo concreto de la influencia del paradigma cliente-usuario en la política criminal, lo observamos en la descripción que ha hecho la literatura acerca de cómo las víctimas en el sistema penal se han convertido en un verdadero grupo de presión para la configuración de la política legislativa penal (Garland, 2005). Para nosotros, desde una perspectiva organizacional, este nuevo rol de las víctimas estaría también fomentado por las propias instituciones del sistema penal, esencialmente por la búsqueda de mejorar su imagen pública mediante la aplicación del paradigma de orientación al cliente.

3.- El estudio de la relación entre género y gestión: Siendo este uno de los ámbitos más relevantes de las actuales líneas de investigación de los sistemas penales, las temáticas tratadas se han centrado esencialmente en aplicar la perspectiva de género en relación a la tutela penal. ${ }^{19}$ En el plano organizacional el tema de género usualmente es enfocado desde la idea de paridad entre funcionarios, especialmente ante la supremacía del género masculino en estas instituciones. Los ECG pueden ofrecer un amplio abanico de posibilidades a otro tipo de interacciones entre género e instituciones penales, especialmente en lo relativo a cómo cambia el comportamiento del sistema de control con tal o cuál componente de género. Esto último usualmente se relaciona con estudios hechos acerca del ámbito policial realizados desde la perspectiva de género. ${ }^{20}$

\section{4.- El estudio de las "relaciones laborales" y la distribución de poder dentro de las}

organizaciones de la justicia penal: Uno de los ámbitos donde la emergencia de la Nueva Gestión Pública ha marcado un hito, es en la distribución de fuerzas y poder entre los funcionarios al interior de las organizaciones; ciertamente este hecho aún esta tímidamente

\footnotetext{
${ }^{19}$ Ejemplo de estudios acerca de esta temática ver en: Faraldo e Iglesias (2010) (coords.), “Género y sistema penal: una perspectiva internacional".

${ }^{20}$ Otras importantes variables sociológicas que pudieran tener un fuerte impacto en las organizaciones de justicia penal son por ejemplo, "el factor racial", (especialmente en las instituciones policiales), o el "factor clase social", o bien, cómo "el machismo" influye en las entidades penales. Otro ámbito similar, es el estudio de "las emociones, personales y colectivas, ligadas al cambio organizacional", por ejemplo, en Gómez y López-Aranguren (2004:332), su extrapolación analítica al campo de las instituciones penales sería bastante lógico, dado que el sistema penal finalmente es una organización con una socialización compleja que se encarga de "gestionar el drama y conflicto social".
} 
González Guarda, C. ¿Es posible una criminología organizacional crítica? Los aportes de los 'Estudios críticos đÐ母 gestión" a la observación político -criminal del sistema penal. Derecho y Ciencias Sociales. Octubre 2017. № 17. (Estudios actuales sobre la justicia penal) Pgs 116-144 ISNN 1852-2971. Instituto de Cultura Jurídica y Maestría en Sociología Jurídica. FCJ y S. UNLP

estudiado en el campo de la justicia penal. De este modo, la sobrecarga laboral, las enfermedades del trabajo, la precariedad laboral, la saturación de metas estadísticas o la falta de capacitación laboral, son algunos fenómenos que derivan de este nuevo escenario organizacional. $^{21}$

También, mediante los ECG es posible estudiar cómo los cuadros funcionariales de la organización adquieren o dejan de adquirir poder organizacional, y cómo su comportamiento se puede convertir en un factor fortalecedor o saboteador de las reformas a la justicia penal. En este mismo contexto es posible entender críticamente todo el amplio abanico de situaciones de "resistencia organizacional" que se producen al interior del sistema penal, tanto del mundo de la judicatura o fiscales, o por los funcionarios de la administración de justicia. ${ }^{22}$

En síntesis, esta línea nos podría permitir adentrarnos en conocer cómo se gestionan y resuelven una diversidad de conflictos organizacionales dentro del sistema penal y cuáles son los efectos político criminales de éstos. Dentro de este mismo ámbito pueden caber a título de ejemplo las tensiones entre policías y funcionarios de justicia, entre fiscales del ministerio público de justicia, entre jueces y fiscales, etc.

\section{5.- El estudio de las relaciones entre gestión, técnica e ideología en los sistemas}

penales: La idea de enfocar e impulsar los estudios organizacionales críticos en el campo de la política criminal y la criminología es beneficiosa, entre otras razones, para contrarrestar esa visión neutral tanto de las políticas públicas como de las tecnologías "gerenciales", como si fueran unas políticas criminales sin ideología. Como indica Ramírez (2000:15) citando a Clegg (1996), siempre es necesario entender "la naturaleza irremediablemente política del management".

La pretendida visión neutral y tecnocrática, especialmente sustentada por la criminología administrativa, que en el último tiempo se ha ido asumiendo sobre el sistema penal es falaz

\footnotetext{
${ }^{21}$ Sobre estos puntos por ejemplo se puede ver el trabajo de Lima Hostensky (2015) "Trabajar bajo la nueva gestión pública de la justicia brasileña: un estudio empírico".

${ }^{22}$ Un caso de resistencia organizacional es el que llevó a cabo la Judicatura a propósito de la reforma a la justicia penal en diversos países latinoamericanos. Por ejemplo, en el caso chileno este es un hecho reconocido por los mismos diseñadores e implementadores de la reforma procesal penal, quienes tuvieron que elaborar estrategias organizacionales novedosas para baipasear esta situación, una de ellas fue centrar la reforma en temas no solamente jurídicos sino también en temas de gestión, ámbito en el cual los magistrados tenían menos conocimientos y por tanto, menos capacidad de maniobra y de resistencia organizacional (Alvear y Blanco 2010; Horwitz y López, 2002).
} 


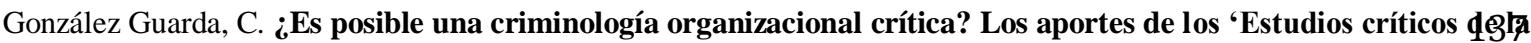
gestión" a la observación político -criminal del sistema penal. Derecho y Ciencias Sociales. Octubre 2017. № 17. (Estudios actuales sobre la justicia penal) Pgs 116-144 ISNN 1852-2971. Instituto de Cultura Jurídica y Maestría en Sociología Jurídica. FCJ y S. UNLP

o al menos incompleta. De hecho, es sabido que existe en las organizaciones la denominada auto-organización (self-organizational), es decir, hay algo más allá de las estructuras técnicas que debemos observar, y que está referido a la forma de gestionar el control sobre los propios sujetos insertos en la organización. ${ }^{23}$ De este modo, precisamente si hay un campo donde por antonomasia se concreta la idea (foucaultiana) de las relaciones entre saber y poder, por tanto entre la técnica, gestión e ideología, es precisamente en el campo de las organizaciones del sistema penal. En este ámbito, como en pocos, el camino que debe recorrer el saber/poder organizacional para implantarse en el sistema de control penal es rápido y de inmediatas consecuencias.

Lo cierto es que no resulta del todo clara la neutralidad de las herramientas de gestión al implementar un determinado modelo de trabajo en una organización penal. Sin embargo, siendo evidente que este es un debate que excede con creces los objetivos de este trabajo, no podemos negar que es un asunto fundamental en las ciencias sociales contemporáneas. Así, los estudios que abordan la relación entre ciencia, tecnología y sociedad son cada más usuales, indicándose en términos generales: que las tecnologías no tienen un carácter neutral sino que nacen dentro de un contexto sociopolítico e, incluso más, están teñidas por la cultura en la cual emergen.

Es evidente que muchas tecnologías y modelos de gestión, terminan utilizándose en ámbitos para los cuales no fueron inicialmente pensadas ni diseñadas, lo que es palpable en las nuevas tecnologías de la información (TICs) por ejemplo, que se aplican en cada vez más ámbitos de la sociedad. En el caso de las herramientas de gestión, estas son básicamente una tecnología que nace y se desarrolla en el mundo privado para especificas necesidades de gestión empresarial. Una vez asimiladas en el campo del sistema penal estas tecnologías seguirán la inercia punitiva normal y por tanto se adaptarán a los fines de control penal del sistema.

\section{6.- Investigación acerca del "lenguaje del cambio organizacional" en el sistema penal:}

Este punto se relaciona esencialmente con el discurso o retórica del cambio en las organizaciones de justicia penal. Por tanto, aquí se pretende dilucidar cómo se comporta

\footnotetext{
${ }^{23}$ Aunque la relación entre tecnología, gestión y sistema penal es amplia, un campo donde esto adquiere mayor implicancia punitiva es en la corriente criminológica denominada "Electronic Monitoring". Así el debate se ha centrado en la gestión del aumento de seguridad basado en criterios económicos, en el costo y eficiencia penitenciaria y en la monitorización para optimizar recursos. Sobre esta cuestión ver en Nellis, M., Beyens, K., Kaminski, D. (2013). Electronically Monitored Punishment: International and Critical Perspectives. Y en nuestro contexto por ejemplo ver en Arenas García, L. (2017). Los medios de control telemáticos en el sistema penal español.
} 
González Guarda, C. ¿Es posible una criminología organizacional crítica? Los aportes de los 'Estudios críticos dÐ⿻ gestión" a la observación político -criminal del sistema penal. Derecho y Ciencias Sociales. Octubre 2017. № 17. (Estudios actuales sobre la justicia penal) Pgs 116-144 ISNN 1852-2971. Instituto de Cultura Jurídica y Maestría en Sociología Jurídica. FCJ y S. UNLP

este fenómeno y de qué manera realmente penetra en las instituciones. Determinando así de qué forma esa retórica del cambio organizacional tiene efectos político criminales tangibles en el sistema penal, desacoplándose por tanto de los efectos exclusivamente técnicos-organizacionales. ${ }^{24}$ Un ejemplo de esto sería el estudio del denominado "lenguaje managerial" referido a cómo entender el rol de los directivos o mánagers judiciales (administradores) dentro de las organizaciones de justicia, o averiguar cómo los operadores del sistema de justicia penal (por ejemplo, fiscales o jueces) incorporan retórica gerencial en su racionalidad jurídica, o bien, a entender cómo la literatura (de los gurús) contemporánea del management se materializa en la forma de manejar en general a las organizaciones de justicia penal.

\section{7.- Las contradicciones, paradojas y ambigüedades en la implantación de los modelos} de gestión en el sistema penal. Choque de racionalidades: Esta cuestión es especialmente relevante en el caso de la implantación de nuevos modelos de gestión y nuevas formas de trabajo en las organizaciones de justicia penal. Un caso recurrente es la idea de que bajo modelos organizacionales "supuestamente" científicos se obtendrían mayores réditos de racionalidad penal, cuando en realidad es posible que se produzca el efecto contrario de mayor punibilidad.

Esta temática surge en gran parte por el choque que se da entre la racionalidad jurídica, propia del campo normativo penal y de sus operadores específicos, y por otro lado, una racionalidad gerencial, esenciamente operada por profesionales formados en el campo de las ciencias económicas y administrativas, o bien ingenieriles. Ambas racionalidades pugnan por protagonizar los actuales procesos de transformación del sistema de justicia penal, pretendiendo expresarse en las numerosas innovaciones dadas en el campo estadístico, informático y en general, en el manejo de la información del sistema penal. Esta "nueva modernidad penal" ha traído en algunos casos una serie de beneficios en cuanto a organización y transparencia del sistema, pero no necesariamente en cuanto a modificar la estructura criminológica sobre la cual ha sido aplicada, por ello, parece cada vez más evidente que, al menos en Latinoamérica, las necesarias reformas organizacionales a la justicia penal han trasuntado en más punibilidad en los delitos

\footnotetext{
${ }^{24}$ Por ejemplo ver en Gómez y López-Aranguren (2004), "la retórica del cambio en las organizaciones. Un análisis aplicado".
} 
González Guarda, C. ¿Es posible una criminología organizacional crítica? Los aportes de los 'Estudios críticos dÐb gestión" a la observación político -criminal del sistema penal. Derecho y Ciencias Sociales. Octubre 2017. № 17. (Estudios actuales sobre la justicia penal) Pgs 116-144 ISNN 1852-2971. Instituto de Cultura Jurídica y Maestría en Sociología Jurídica. FCJ y S. UNLP

clásicos y de las clases más desfavorecidas, y menos en la modificación del estatus quo criminológico. $^{25}$

\section{8.- Estudios acerca de la "cultura organizacional" de las instituciones de justicia}

penal: En este punto procede determinar si nos encontramos ante culturas organizacionales diferentes, como por ejemplo, la cultura organizacional policial, o la judicial, o del Ministerio Público. O bien, si dentro de estos mismos estamentos se dan procesos socioorganizacionales diferenciados entre estamentos superiores, medios o inferiores. De la misma forma se podría escrutar en las relaciones que se dan entre estas diferentes culturas presentes en la organización, y analizar cuáles son los eventuales efectos político criminales de las mismas. Lo cierto es que hablar de cultura organizacional resulta genérico considerando su extensión en la literatura respectiva (por ejemplo, Osca, 2004 y Gil y Alcovar, 2003), por eso, es innegable que dentro de su concepto sería posible integrar parcialmente diversos elementos que hemos indicado en otros puntos de este texto. ${ }^{26}$

\section{9.- El debate acerca de lo público y privado en las organizaciones de justicia: Uno de}

los grandes debates existentes en este campo, se refiere a la existencia o no de dos management, uno público y otro privado. La mayoría de los autores afirma que este fenómeno se explica debido al traspaso de lógicas y conocimientos, desde lo privado a lo público. Otros en cambio postulan que esto habría ocurrido a la inversa (Guerrero, 2009). Sin embargo, a pesar de que hoy en día las relaciones entre estos dos mundos parecen ser más estrechas de lo que se piensa, la diferencia persiste, especialmente en lo que respecta a los objetivos que se marcan ambos ámbitos, lo cual debería influir finalmente en los estilos diversos de gestionar.

Así, en el campo de lo público, donde evidentemente insertamos los objetivos pretendidos por la política criminal, de un tiempo a esta parte, los problemas de la criminalidad son manejados con formulas mixtas (concesiones, externalizaciones, etc.), lo que demuestra

\footnotetext{
${ }^{25}$ La descripción de algunos de estos fenómenos los podemos observar por ejemplo en: Borges Fortes, $\mathrm{P}$, (2015). How legal indicators influence a justice system and judicial beahavior: the Brazilian National Council of justice and "justice in numbers".

${ }^{26}$ Investigaciones desarrolladas desde la "sociología del campo jurídico", como la de Hersant, J., (2014), "Una sociología de los funcionarios del Poder Judicial chileno en el contexto de la Reforma Procesal Penal", exploran las diferentes formas en que sociabilizan los agentes del campo jurídico. En el caso del trabajo citado basándose en lo preceptuado por Michael Lipsky en Street-level bureaucracy: dilemmas of the individual in public services. 30th anniversary expanded edition (2010), escruta como han impactado las recientes reformas judiciales llevadas a cabo en Chile en los funcionarios y empleados de "bajo nivel", especialmente en cuanto a sus "identidades profesionales" y a los nuevos códigos organizacionales adquiridos producto de estas transformaciones jurídicas.
} 
González Guarda, C. ¿Es posible una criminología organizacional crítica? Los aportes de los 'Estudios críticos deł gestión" a la observación político -criminal del sistema penal. Derecho y Ciencias Sociales. Octubre 2017. № 17. (Estudios actuales sobre la justicia penal) Pgs 116-144 ISNN 1852-2971. Instituto de Cultura Jurídica y Maestría en Sociología Jurídica. FCJ y S. UNLP

que existe cierta tendencia que más que centrarse en definiciones u objetivos sustanciales, miran a la forma en que estas son manejadas y gestionadas. Esto nos obliga, independientemente de las valoraciones ideológicas que se tengan del sistema penal, a una observación y estudio de la naturaleza de las herramientas de gestión (pública o privada) que finalmente se movilizarán para lograr los objetivos materiales del sistema.

Lo anterior no solo es relevante para arrojar luz respecto de las definiciones estructurales entre público y privado, sino también a la hora explorar el rol que juegan la ideología de los operadores en el desarrollo y evolución del sistema penal, y cómo estos pueden transformarse en aliados de los cambios o en verdaderos saboteadores de los mismos. Lo cual se puede resumir en la idea del grado de fidelidad con los cambios organizacionales.

\section{0.- Estudio acerca del nivel de participación (empowerment) de los diversos} estamentos dentro de las instituciones de justicia penal: Esta perspectiva busca reflexionar acerca del real compromiso institucional en las transformaciones organizacionales y de cómo influye esto en los procesos político criminales respectivos. De este modo, se puede ver si los procesos de cambios organizativos tienen un tiempo limitado de intensidad, para luego caer en la rutina, la entropía y finalmente en una organización distinta.

En relación con lo anterior es relevante observar la existencia de verdaderos "procesos organizacionales de ficción", entendiendo por ellos el proceso de cómo la organización construye un "relato organizacional-penal simbólico" que luego no tiene correlato en la realidad. Ejemplos de esta situación los encontramos con frecuencia en los objetivos pretendidos por las planificaciones estratégicas ${ }^{27}$ que no tienen aplicación en la materialidad de la organización, pero que dan la imagen de cohesión institucional. Situación similar ocurre con los programas de capacitación impulsados por las organizaciones de justicia que en muchos casos no se trasladan a una mejora real del servicio, pero que otorgan un espejismo de modernidad. De este modo, las organizaciones corren el riesgo de caer en la desidia en estas transformaciones, reinventado viejos modelos

\footnotetext{
${ }^{27}$ La planificación estratégica es una herramienta de gestión plenamente aplicada en los sistemas de justicia en Latinoamérica, consolidándose mediante una serie de cumbres de todos los países latinoamericanos, además de España y Portugal”. Respecto de la planificación estratégica ver en: http://www.cumbrejudicial.net/web/guest/xviiedicion/grupos?p_p_id=20\&p_p_lifecycle=0\&p_p_state=maxi mized\&p_p_mode=view\&_20_struts_action=\%2Fdocument_library\%2Fview\&_20_folderId=446059.
} 
González Guarda, C. ¿Es posible una criminología organizacional crítica? Los aportes de los 'Estudios críticos dę ła gestión" a la observación político -criminal del sistema penal. Derecho y Ciencias Sociales. Octubre 2017. № 17. (Estudios actuales sobre la justicia penal) Pgs 116-144 ISNN 1852-2971. Instituto de Cultura Jurídica y Maestría en Sociología Jurídica. FCJ y S. UNLP

de gestión en supuestos nuevos programas de innovación a efectos de mantener vigente aquel "relato organizacional-penal". ${ }^{28}$

La discusión acerca de la real participación de los integrantes de las organizaciones de justicia penal nos lleva a uno de los núcleos teóricos más relevantes de los ECG, el denominado proceso de "emancipación". Este proceso lo podemos comprender de la siguiente manera: "La emancipación describe el proceso a través del cual los individuos y grupos se liberan de condiciones sociales e ideológicas represivas, en particular de aquéllas que ponen restricciones socialmente innecesarias sobre el desarrollo y la articulación de la consciencia humana" (Alvesson \& Willmott, 1992: 432).

La conexión directa entre la emancipación y lo propugnado por Foucault y la escuela de la Teoría crítica es evidente; el propio Alvesson se esfuerza por explicar el concepto de micro-emancipación. Quizás por ello "se trata, no ya de emprender un proyecto global de liberación, sino pequeños microproyectos que aprovechen los espacios anti-emancipatorios de resistencia (Ball, 2005; Fleming \& Spicer, 2003) que se encuentran aquí y allá en la vida diaria en las organizaciones" (Saavedra, 2009: 57). Esto en el sistema penal cobra relevancia a objeto de estudiar el grado de libertad y la capacidad de emancipación que los sujetos (operadores esencialmente) tienen en relación a lo que establecen las organizaciones, así, es normal que vía prácticas y rutinas propias lo que se produzca normalmente son procesos de auto-organización de las instituciones penales.

\section{5.- Conclusión}

Este trabajo ha explorado la posibilidad de tender puentes entre los nacientes estudios organizacionales críticos y el sistema penal. Ciertamente estamos ante un renovado campo teórico y metodológico que nos mueve a investigar muchas zonas que hasta ahora no eran mayormente tratadas por las visiones tradicionales de la política criminal, tales como temas de género, temas raciales, la implicancia político criminal de la vida emocional de los operadores de justicia, problemas laborales, transformaciones estadísticas, la influencia del

${ }^{28}$ El estilo de planificación estratégica actualmente predominante es la "planificación estratégica participativa", la cual consiste en elaborar el Plan estratégico incorporando la perspectiva de la mayor cantidad de cuadros funcionariales de la entidad respectiva. Lo usual es que se realicen "talleres" que son llevados a cabo desde las estructuras organizacionales más básicas hasta las jerarquías gerenciales del sistema, y que pretenden que en esas instancias se pueda discutir el futuro de la organización. Sin perjuicio de sus intenciones, lo cierto es que dada la jerarquía del sistema, así como el monopolio en la fijación de la política-criminal por parte del nivel directivo, esta modalidad de elaboración de planificación estratégica tiene más bien un carácter simbólico, con miras a "alinear" internamente "ciertas" visiones organizacionales, en lugar de ser una especie de "asambleísmo" o democracia organizacional. 
González Guarda, C. ¿Es posible una criminología organizacional crítica? Los aportes de los 'Estudios críticos dęa gestión" a la observación político -criminal del sistema penal. Derecho y Ciencias Sociales. Octubre 2017. № 17. (Estudios actuales sobre la justicia penal) Pgs 116-144 ISNN 1852-2971. Instituto de Cultura Jurídica y Maestría en Sociología Jurídica. FCJ y S. UNLP

gerencialismo, etc. En este trabajo hemos asumido inicialmente, que todo este nuevo andamiaje de temáticas y conocimientos pudiera ser útil especialmente para aquellos trabajos inspirados en posiciones críticas del control penal, pero ciertamente, y aquí me adelanto a objeciones futuras, sería posible que cualquier perspectiva del sistema penal este habilitada a utilizar estas herramientas de investigación.

A efectos de concretar esta exploración hemos expuesto un catálogo, no cerrado, de potenciales temáticas presentes en el sistema penal y que pueden ser abordadas por los estudios críticos de la gestión. Como es lógico, en trabajos venideros ellas podrán ser ampliadas, modificadas o considerarse lisa y llanamente equivocadas. De todas maneras, creemos que constituyen un piso mínimo a efectos de presentar esta corriente de investigación en la política criminal contemporánea.

\section{Bibliografía:}

Aebi. M. F. (2008). Temas de criminología. Madrid: Dikinson.

Alcadipani, R., Farzad, R., Khan, Gantman, E. y Stella, N., (2012). voices in management and organization knowled in management and organization knowledge. Organization. 19 (2). pp. 132-143.

Alvear Valenzuela, S y Blanco Suarez, R. (2010). Diálogos sobre la reforma procesal penal, Santiago de Chile: Ediciones Universidad Alberto Hurtado.

Alvesson, M y Willmott, H, (2003). Studying management critically. London: Sage Publications.

Arenas García, L. (2017). Los medios de control telemáticos en el sistema penal español. Tesis doctoral. Universidad de Málaga. (tesis en proceso de publicación).

Barzelay, Michel. (1992). Gestión pública estratégica: Concepto, análisis y experiencias. El caso IPIA. Madrid: Instituto de estudios fiscales.

Binder, A. M. (1991). El proceso penal, San José, ILANUD.

Binder, A. M. (1993). Introducción al derecho procesal penal, Buenos Aires, editorial. Ad-hoc.

Maier, J. B., Ambos, K., Woischnik, J. (2000). Las reformas procesales penales en América Latina. Buenos Aires: Editorial ad-hoc.

Binder, Alberto, (2010). La política criminal en el marco de las políticas públicas. Bases para el análisis político criminal. Revista de estudios de la justicia. $\mathrm{N}^{\mathrm{o}} 12$.

Borges Fortes, P, (2015). How legal indicators influence a justice system and judicial beahavior: the Brazilian National Council of justice and "justice in numbers". The Journal of Legal Pluralism and Unofficial Law, 47:1, 39-55.

Bustos, Juan y Hormazábal, Hernán, (2004). Nuevo sistema de derecho penal. España. Trotta. 
González Guarda, C. ¿Es posible una criminología organizacional crítica? Los aportes de los 'Estudios críticos deł 3 gestión" a la observación político -criminal del sistema penal. Derecho y Ciencias Sociales. Octubre 2017. № 17. (Estudios actuales sobre la justicia penal) Pgs 116-144 ISNN 1852-2971. Instituto de Cultura Jurídica y Maestría en Sociología Jurídica. FCJ y S. UNLP

Bustos, Juan y Hormazábal, Hernán. (1997). Lecciones de derecho penal. Madrid. Editorial Trotta. Vol. 1.

Chias, J. (1995). Marketing Público. Por un gobierno y una administración al servicio del público. España: McGraw-Hill.

Cubells, J. e Íñiguez, L. (2008), La construcción de hechos en el discurso jurídico: Análisis del caso de los "robos en cajeros automáticos en la ciudad de Barcelona". Revista Española de Investigación Criminológica. Art. 4. Nº 6 .

Díez Ripollés, J. L., (2011). Dimensión exclusión/inclusión social como guía de la política criminal comparada. Revista Electrónica de Ciencia Penal y Criminología. No 13.12. Pp:136.

Espinosa, F. y Rivera, G, (2015). Los estudios críticos de la administración en Chile. Recuperado de Criticalmanegement.org.

Fernández Rodríguez, C. J, (2007a). "Estudios críticos de la gestión: una visión general”. En Fernández, C. J, (Ed). Vigilar y organizar. Una introducción a los critical management studies. Madrid: Siglo 21. pp. 339-383.

Fernández Rodríguez, C. J, (2007b). El discurso del management: tiempo y narración. Madrid: Centro de Investigaciones Sociológicas (CIS):

Fernández Rodríguez, C. J, (2008). Management y sociedad en la obra de Peter Drucker. Revista internacional de sociología RIS. Vol. LXVI. No 49. pp. 195-218.

Fernández, F., (2004). Gestión pública. Organización de los tribunales y del despacho judicial. Instituto de estudios fiscales. Doc. No 7/04. pp. 1-26.

Gil y Alcovar (2003). Introducción a la Psicología de las Organizaciones. Madrid: Alianza Editorial.

Gómez Rodríguez, C y López-Aranguren, E (2004). La retórica del cambio en las organizaciones. Un análisis aplicado. Centro de Investigaciones Sociológicas. Madrid.

González Guarda, C. J, (2017). La política criminal aplicada (PCA): La deriva de la política criminal hacia la política pública. Nuevo Foro Penal, 13(88), 185-216.

González Guarda, C. J. (2016). Hacia un nuevo modelo organizacional del sistema de justicia penal en Latinoamérica. La influencia del management y del gerencialismo en esta reconfiguración. Revista Nova Criminis, Universidad Central de Chile.

Guerrero, O, (2009). El fin de la nueva gerencia pública. Revista Chilena de Administración Pública. $\mathrm{N}^{\circ} 13$.

Hersant, J., (2014), "Una sociología de los funcionarios del Poder Judicial chileno en el contexto de la Reforma Procesal Penal”. En Salvador Millaleo, Juan Carlos Oyanedel, Daniel Palacios y Hugo Rojas (eds.) Sociología del derecho en Chile. Libro homenaje a Edmundo Fuenzalida. Santiago de Chile: Ediciones Universidad Alberto Hurtado, 2014, Pp. 160-174.

Hoque, Z., y W. James, (2000): Linking Balanced Scorecard Measures to Size and Market Factors: Impact on Organizational Performance. Journal of Management Accounting Research. Vol. 12. № 1. pp. 1-17.

Larrauri, E. (2000). La herencia de la criminología crítica. Madrid: Siglo XXI Editores. 
González Guarda, C. ¿Es posible una criminología organizacional crítica? Los aportes de los 'Estudios críticos dę4 gestión" a la observación político -criminal del sistema penal. Derecho y Ciencias Sociales. Octubre 2017. № 17. (Estudios actuales sobre la justicia penal) Pgs 116-144 ISNN 1852-2971. Instituto de Cultura Jurídica y Maestría en Sociología Jurídica. FCJ y S. UNLP

Le Bonniec, F, (2014). ¿Hay discriminación en los tribunales del sur de Chile? Razones para una etnología del campo jurídico en la Araucanía. En Millaleo, O, Oyanedel, J.C, Palacios, D y Rojas, H, (edits.). Sociología de derecho en Chile. Libro homenaje a Edmundo Fuenzalida. Editorial Universidad Alberto Hurtado. Pp. 175-195.

Lima Hostensky, E. (2015). Trabajar bajo la nueva gestión pública de la justicia brasileña: un estudio empírico. Tesis doctoral. Facultad de Sicología. Barcelona: Universidad Autónoma de Barcelona

Lipe, M., y S. Salterio, (2000): The Judgmental Effects or the Balanced Scorecard's Information Organization and Diversity. The Accounting Review, 75 (3). pp. 283-298.

Lipe, M., y S. Salterio, (2002): A Note on the Judgmental Effects or the Balanced Scorecard's Information Organization. Accounting Organizations and Society, 27. pp. 531540

Nellis, M., Beyens, K., Kaminski, D. (2013). Electronically Monitored Punishment: International and Critical Perspectives. London: Routledge.

Osca, A, (2004). Psicología de las Organizaciones. Madrid: Sanz y Torres

Ramírez, L, (2004). Hacia un análisis critico de la gestión. Presentando los critical management studies. Revista Chilena de Administración Pública. Vol. II, No 4. pp. 7-25.

Saavedra, J, (2009). Descubriendo el lado oscuro de la gestión. Los critical management studies o una nueva forma de abordar los fenómenos organizacionales. Rev. Fac. Cienc. Econ. Vol. XVII (2). pp. 45-60.

Salinas, R, (2000). Violencias sexuales e interpersonales en el Chile tradicional, Revista de Historia Social y de las Mentalidades, No 4, Pp: 175-195.

Sanjurjo, L. (2016). Las luchas por las memorias en la escena judicial: Una mirada etnográfica sobre los Juicios de Crímenes de Lesa Humanidad. Cuadernos de antropología social, (43), 161-177. Recuperado en 02 de octubre de 2017, de http://www.scielo.org.ar/scielo.php?script=sci_arttext\&pid=S1850-

275X2016000100012\&lng=es\&tlng=es.

Solarte, L, (2013). "Management crítico: una respuesta a la praxis y epistemología del management dominante". En Carvajal, Rafael (Ed). Estudios críticos de la organización: Qué son y cuál es su utilidad. Cali: Universidad del Valle, facultad de ciencias de la administración. pp. 227-238.

Subirats, J. (1994). Análisis de políticas públicas y eficacia de la administración. Madrid: Ministerio para las administraciones públicas.

Taylor, I., Walton, P., y Young, J. (1981). Criminología crítica. Madrid: Siglo XXI editores.

Van Swaaningen, R. (2011). Perspectivas europeas para una criminología crítica. Buenos Aires: BdeF Ltda.

Zugaldía y Marín de Espinosa, (2015). La responsabilidad criminal de las personas jurídicas en Latinoamérica y España. Madrid: Editorial Aranzadi. 